Article

\title{
Identification and Characterization of Mycemycin Biosynthetic Gene Clusters in Streptomyces olivaceus FXJ8.012 and Streptomyces sp. FXJ1.235
}

\author{
Fangying Song ${ }^{1,2}$, Ning Liu ${ }^{1}$, Minghao Liu ${ }^{1}$, Yihua Chen ${ }^{1}$ and Ying Huang ${ }^{1, *(1)}$ \\ 1 State Key Laboratory of Microbial Resources, Institute of Microbiology, Chinese Academy of Sciences, \\ Beijing 100101, China; songfangying_@126.com (F.S.); fussliu@126.com (N.L.); lysf1987313@163.com (M.L.); \\ chenyihua@im.ac.cn (Y.C.) \\ 2 College of Life Sciences, University of Chinese Academy of Sciences, Beijing 100049, China \\ * Correspondence: huangy@im.ac.cn; Tel./Fax: +86-10-6480-7311
}

Received: 13 February 2018; Accepted: 15 March 2018; Published: 20 March 2018

\begin{abstract}
Mycemycins A-E are new members of the dibenzoxazepinone (DBP) family, derived from the gntR gene-disrupted deep sea strain Streptomyces olivaceus FXJ8.012 1741 and the soil strain Streptomyces sp. FXJ1.235. In this paper, we report the identification of the gene clusters and pathways' inference for mycemycin biosynthesis in the two strains. Bioinformatics analyses of the genome sequences of S. olivaceus FXJ8.012 $\Delta 1741$ and S. sp. FXJ1.235 predicted two divergent mycemycin gene clusters, mym and mye, respectively. Heterologous expression of the key enzyme genes of mym and genetic manipulation of mye as well as a feeding study in S. sp. FXJ1.235 confirmed the gene clusters and led to the proposed biosynthetic pathways for mycemycins. To the best of our knowledge, this is the first report on DBP biosynthetic gene clusters and pathways.
\end{abstract}

Keywords: mycemycin; dibenzoxazepinone; biosynthesis; gene cluster; pathway; Streptomyces

\section{Introduction}

Dibenzoxazepinones (DBPs) constitute an important family of heterocyclic compounds with two aromatic ring systems [1]. DBPs exhibit various bioactivities, including antitumor, antioxidant, anti-HIV reverse transcriptase, etc. [1,2], which have encouraged researchers to put considerable effort into the synthesis of DBP skeletons [3-6]. However, there have been few cases of either natural DBPs or their biosyntheses.

In our previous work, we reported mycemycins A-E (Figure 1) as new members of the DBP family with weak inhibitory activity on HIV-1 reverse transcriptase [7]. Mycemycins A and B were isolated from an acidic, red soil-derived strain Streptomyces sp. FXJ1.235 and mycemycins C-E from a gntR gene-disrupted deep sea strain, Streptomyces olivaceus FXJ8.012 1741 . All the mycemycins are either mono- or bis-chlorinated derivatives except mycemycin A. Mycemycin B is mono-chlorinated at the $\mathrm{R}_{4}$ position, while mycemycin $\mathrm{D}$ is mono-chlorinated at the $\mathrm{R}_{2}$ position. Mycemycins $\mathrm{C}$ and $\mathrm{E}$ are chlorinated at both positions (Figure 1). These chemical structures indicate that different halogenation modifications might occur during mycemycin biosynthesis in S. olivaceus FXJ8.012 1741 and S. sp. FXJ1.235. To gain an understanding of the biosynthetic processes of DBPs, in this study, we identified mycemycin biosynthetic gene clusters and proposed biosynthetic pathways in the two different Streptomyces strains by genome analysis, heterologous expression, genetic manipulation, and precursor feeding. Our results show that, although they contain a series of homologs and code for similar pathways, the gene clusters responsible for mycemycin biosynthesis in the two strains are different in both arrangement and content. The marine-derived strain, S. olivaceus FXJ8.012 $\Delta 1741$, possesses a 
continuous secondary biosynthetic gene cluster for mycemycins, while the soil-derived strain, $S$. sp. FXJ1.235, has a discontinuous mycemycin gene cluster that recruited two primary metabolic genes.<smiles>[R]C(=O)c1cc([R2])c([R3])c2c1NC(=O)c1cc([R4])ccc1O2</smiles>
A $\mathrm{R}_{1}=\mathrm{OMe}, \mathrm{R}_{2}=\mathrm{R}_{3}=\mathrm{R}_{4}=\mathrm{H}$
B $\mathrm{R}_{1}=\mathrm{OMe}, \mathrm{R}_{2}=\mathrm{R}_{3}=\mathrm{H}, \mathrm{R}_{4}=\mathrm{Cl}$
C $\mathrm{R}_{1}=\mathrm{OMe}, \mathrm{R}_{2}=\mathrm{Cl}, \mathrm{R}_{3}=\mathrm{CH}_{3}, \mathrm{R}_{4}=\mathrm{Cl}$
D $\mathrm{R}_{1}=\mathrm{NH}_{2}, \mathrm{R}_{2}=\mathrm{Cl}, \mathrm{R}_{3}=\mathrm{CH}_{3}, \mathrm{R}_{4}=\mathrm{H}$
E $\mathrm{R}_{1}=\mathrm{NH}_{2}, \mathrm{R}_{2}=\mathrm{Cl}, \mathrm{R}_{3}=\mathrm{CH}_{3}, \mathrm{R}_{4}=\mathrm{Cl}$

Figure 1. Structures of mycemycins A-E [7].

\section{Results and Discussion}

\subsection{Sequence Analyses and Gene Organizations of the Mycemycin Biosynthetic Gene Clusters}

To find the putative gene clusters for mycemycins in S. olivaceus FXJ8.012 $\Delta 1741$ and $S$. sp. FXJ1.235, we sequenced the genomic DNAs of the two strains and searched the draft genome sequences for halogenase-encoding genes. Two putative halogenase genes, mymM and $m y m P$, were found in S. olivaceus FXJ8.012 1741 , while only one candidate, myeP, was present in $S$. sp. FXJ1.235. Comparative sequence analyses of the proteins encoded by the genes flanking these putative halogenase genes revealed that they were likely involved in the biosynthesis of mycemycins. In S. olivaceus FXJ8.012 1741 , the predicted gene cluster (mym) contained 20 open reading frames (ORFs) spanning a $\sim 26.8 \mathrm{~kb}$ continuous region (Figure 2 and Table 1). However, in S. sp. FXJ1.235 the predicted cluster (mye) seemed truncated, containing only 14 ORFs in a continuous region with a rearranged gene order, compared to their counterparts in mym (Figure 2 and Table S1). Two important mym genes, $m y m C$ and $m y m Q$, which encode the putative tryptophan 2,3-dioxygenase (TDO) and kynureninase $(\mathrm{KYN})$, respectively, were missing in the truncated mye cluster. TDO has been reported to catalyze the conversion of tryptophan (Trp) to $N$-formylkynurenine (NFK) [8,9], while KYN is responsible for the hydrolytic cleavage of the side chain from both 3-hydroxykynurenine and kynurenine to produce 3-hydroxyanthranilate and anthranilic acid, respectively [10]. These two processes are not only essential during the primary metabolism of kynurenine but also are involved in the precursor supply of many antibiotic biosyntheses [11-13]. Accordingly, they are most likely to be indispensable for mycemycin biosynthesis. Additional searches of the genome sequences resulted in the identification of a copy of TDO- and KYN-encoding genes in S. sp. FXJ1.235 and an additional copy of both genes in S. olivaceus FXJ8.012 $\Delta 1741$, which were located in different genome scaffolds from those encompassing the predicted mycemycin gene clusters. That is, the genome of S. olivaceus FXJ8.012 $\Delta 1741$ carried two copies of both TDO- and KYN-encoding genes, with one copy (mymC and mymQ) located in the $m y m$ gene cluster. However, the genome of $S$. sp. FXJ1.235 contained only one copy of the two genes, myeC and myeQ, respectively. The myeC and myeQ genes were adjacent to each other and located at least 270 $\mathrm{kb}$ away from the partial mye cluster, according to their positions in the genome scaffolds. Therefore, we speculated that myeC and myeQ were responsible for both the biosynthesis of mycemycins and the primary metabolism process in S. sp. FXJ1.235. 


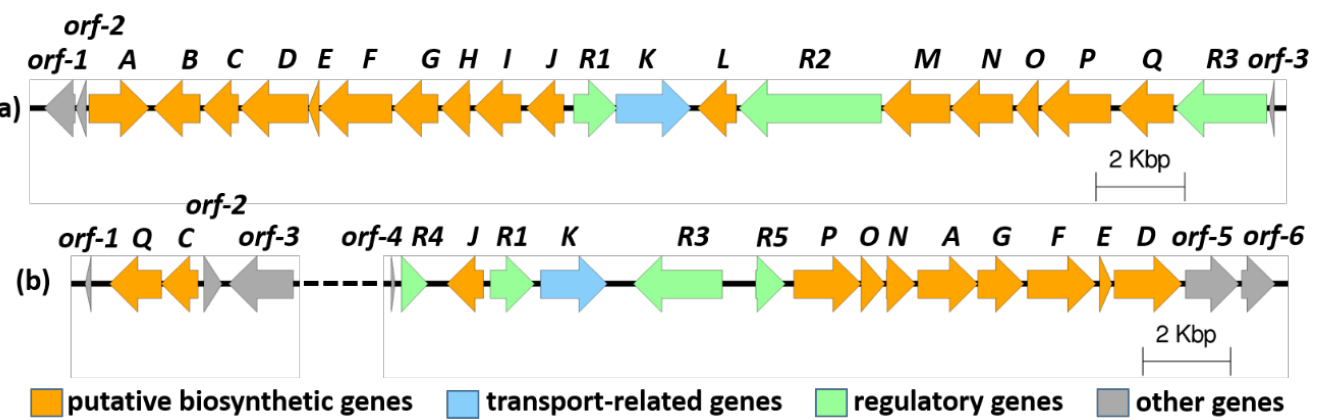

Figure 2. Organization of the mycemycin biosynthetic gene clusters in S. olivaceus FXJ8.012 $\Delta 1741$ (a) and S. sp. FXJ1.235 (b). The dotted line represents a distance of $>270 \mathrm{~kb}$ in the genome.

Table 1. Genes and proteins involved in mycemycin biosynthesis and their putative functions in S. olivaceus FXJ8.012 $\Delta 1741$.

\begin{tabular}{|c|c|c|c|c|}
\hline Gene & Size (AA) & $\begin{array}{l}\text { Protein Homolog and Origin } \\
\text { (Identity/Similarity) }\end{array}$ & $\begin{array}{l}\text { Homolog in mye } \\
\text { (Identity/Similarity) }\end{array}$ & Proposed Function \\
\hline orf-1 & 231 & WP_011030904.1 (89/95); Streptomyces coelicolor & - & Hypothetical protein \\
\hline orf-2 & 78 & None predicted in NCBI & - & Unknown \\
\hline$m y m A$ & 454 & $\begin{array}{c}\text { SsfH, ADE34507.1 (55/68); Streptomyces sp. } \\
\text { SF2575 }\end{array}$ & myeA $(53 / 66)$ & Salicylate synthase \\
\hline$m y m B$ & 351 & $\begin{array}{c}\text { SibL, ACN39735.1 ( } 65 / 76) ; \text { Streptosporangium } \\
\text { sibiricum }\end{array}$ & - & Methyltransferase \\
\hline$m y m C$ & 269 & $\begin{array}{l}\text { SibP, ACN39739.1 ( } 59 / 70) ; \text { Streptosporangium } \\
\text { sibiricum }\end{array}$ & myес $(38 / 53)$ & $\begin{array}{l}\text { Tryptophan 2,3-dioxygenase } \\
\text { (TDO) }\end{array}$ \\
\hline mymD & 513 & $\begin{array}{c}\text { EFL38513.1 (61/71); Streptomyces griseoflavus } \\
\text { Tu4000 }\end{array}$ & myeD $(62 / 76)$ & Amidohydrolase \\
\hline mymE & 82 & $\begin{array}{c}\text { EsmD3, AFB35628.1 (48/61); Streptomyces } \\
\text { antibioticus }\end{array}$ & myeE $(49 / 63)$ & $\begin{array}{l}\text { Phosphopantetheine-binding } \\
\text { protein }\end{array}$ \\
\hline mymF & 547 & $\begin{array}{c}\text { PchD, NP_252918.1 (48/61); Pseudomonas } \\
\text { aeruginosa PAO1 }\end{array}$ & myeF $(61 / 73)$ & $\begin{array}{l}\text { 2,3-dihydroxybenzoate-AMP } \\
\text { ligase }\end{array}$ \\
\hline$m y m G$ & 339 & $\begin{array}{c}\text { BomK, ALE27503.1 (52/70); Streptomyces sp. } \\
\text { NRRL } 12068\end{array}$ & myeG $(60 / 76)$ & $\begin{array}{l}\text { Beta-ketoacyl-ACP synthase } \\
\text { (amide bond formation) }\end{array}$ \\
\hline$m y m H$ & 220 & $\begin{array}{l}\text { EFL35401.1 (49/64); Streptomyces } \\
\text { viridochromogenes DSM } 40736\end{array}$ & - & Hypothetical protein \\
\hline mymI & 354 & KUK37103.1 (61/75); Thermacetogenium phaeum & - & $\begin{array}{l}\text { 3-deoxy-7-phosphoheptulonate } \\
\text { synthase }\end{array}$ \\
\hline mymJ & 281 & $\begin{array}{l}\text { SCE38941.1 (60/68); Streptomyces sp. } \\
\text { PpalLS-921 }\end{array}$ & myeJ $(63 / 72)$ & $\begin{array}{l}\text { SAM-dependent } \\
\text { methyltransferase }\end{array}$ \\
\hline mymR1 & 329 & $\begin{array}{c}\text { SBU95411.1 (75/86); Streptomyces sp. } \\
\text { OspMP-M45 }\end{array}$ & myeR1 $(75 / 85)$ & $\begin{array}{l}\text { Lrp/AsnC family } \\
\text { transcriptional regulator }\end{array}$ \\
\hline mymK & 563 & $\begin{array}{l}\text { CB02009_orf6, OKJ63402.1 (69/81); } \\
\text { Streptomyces sp. CB02009 }\end{array}$ & myeK $(69 / 79)$ & Multidrug MFS transporter \\
\hline$m y m L$ & 294 & $\begin{array}{l}\text { Carboxylesterase NlhH, ASO22469.1 (50/61); } \\
\text { Actinoalloteichus hoggarensis }\end{array}$ & - & Alpha/beta hydrolase \\
\hline$m y m R 2$ & 1072 & $\begin{array}{l}\text { WP_033441976.1 (38/49); Saccharothrix sp. } \\
\text { NRRL B-16314 }\end{array}$ & - & $\begin{array}{l}\text { SARP family transcriptional } \\
\text { regulator }\end{array}$ \\
\hline mym $M$ & 511 & $\begin{array}{c}\text { PyrH, OSY47217.1 }(61 / 76) ; \text { Streptomyces } \\
\text { platensis }\end{array}$ & - & Tryptophan halogenase \\
\hline$m y m N$ & 464 & SDU28343.1 (53/68); Amycolatopsis keratiniphila & $\begin{array}{c}\text { myeN }(61 / 74 \\
\text { query cover } 56 \%)\end{array}$ & $\begin{array}{l}\text { Sodium/hydrogen exchanger } \\
\text { family }\end{array}$ \\
\hline mymO & 175 & KtzS, ABV56599.1 (59/67); Kutzneria sp. 744 & myeO $(61 / 69)$ & Flavin reductase \\
\hline mymP & 530 & $\begin{array}{c}\text { RebH, 4LU6_A (63/76); Lechevalieria } \\
\text { aerocolonigenes }\end{array}$ & myеP $(75 / 83)$ & Tryptophan halogenase \\
\hline mymQ & 411 & $\begin{array}{c}\text { KynU, NP_250770.1 (44/60); Pseudomonas } \\
\text { aeruginosa PAO1 }\end{array}$ & myeQ $(51 / 64)$ & Kynureninase (KYN) \\
\hline mymR3 & 691 & $\begin{array}{c}\text { SBU95407.1 (56/67); Streptomyces sp. } \\
\text { OspMP-M45 }\end{array}$ & myeR3 $(57 / 68)$ & $\begin{array}{l}\text { SARP family transcriptional } \\
\text { regulator }\end{array}$ \\
\hline orf-3 & 38 & None predicted in NCBI & - & Unknown \\
\hline
\end{tabular}




\subsection{Heterologous Expression of the Key Enzyme Genes of Mym and in Vitro Activity Assay}

We found that the production of mycemycins C-E in FXJ8.012 1741 was unstable when performing genetic manipulation of the mym gene cluster. Thus, we carried out heterologous expression of the key enzyme genes of mym to verify their functions. According to the results of BLASTP [14] searching agains public databases, MymC showed a 59\% identity to SibP, which was proposed to be a putative TDO during the biosynthesis of sibiromycin [15]. Previous studies have indicated that TDO is a member of heme-based dioxygenases and, in addition to catalyzing the conversion of Trp to NFK $[9,16]$, it can also catalyze halogenated Trp, such as 6-fluoro-Trp [9]. To verify the function of $\mathrm{MymC}$, in this study, we cloned and heterologously expressed mymC in E. coli rosetta (DE3). The resulting 35.2-KDa protein was then purified and subjected to an in vitro enzymatic activity assay using either L-Trp or L-5-Cl-Trp as a substrate. Ultra-high-performance liquid chromatography (UHPLC)-High-resolution mass spectrometry (HRMS) analysis of the enzymatic reaction products confirmed that MymC was able to convert not only L-Trp to NFK but also L-5-Cl-Trp to 5-Cl-NFK (Figure 3).

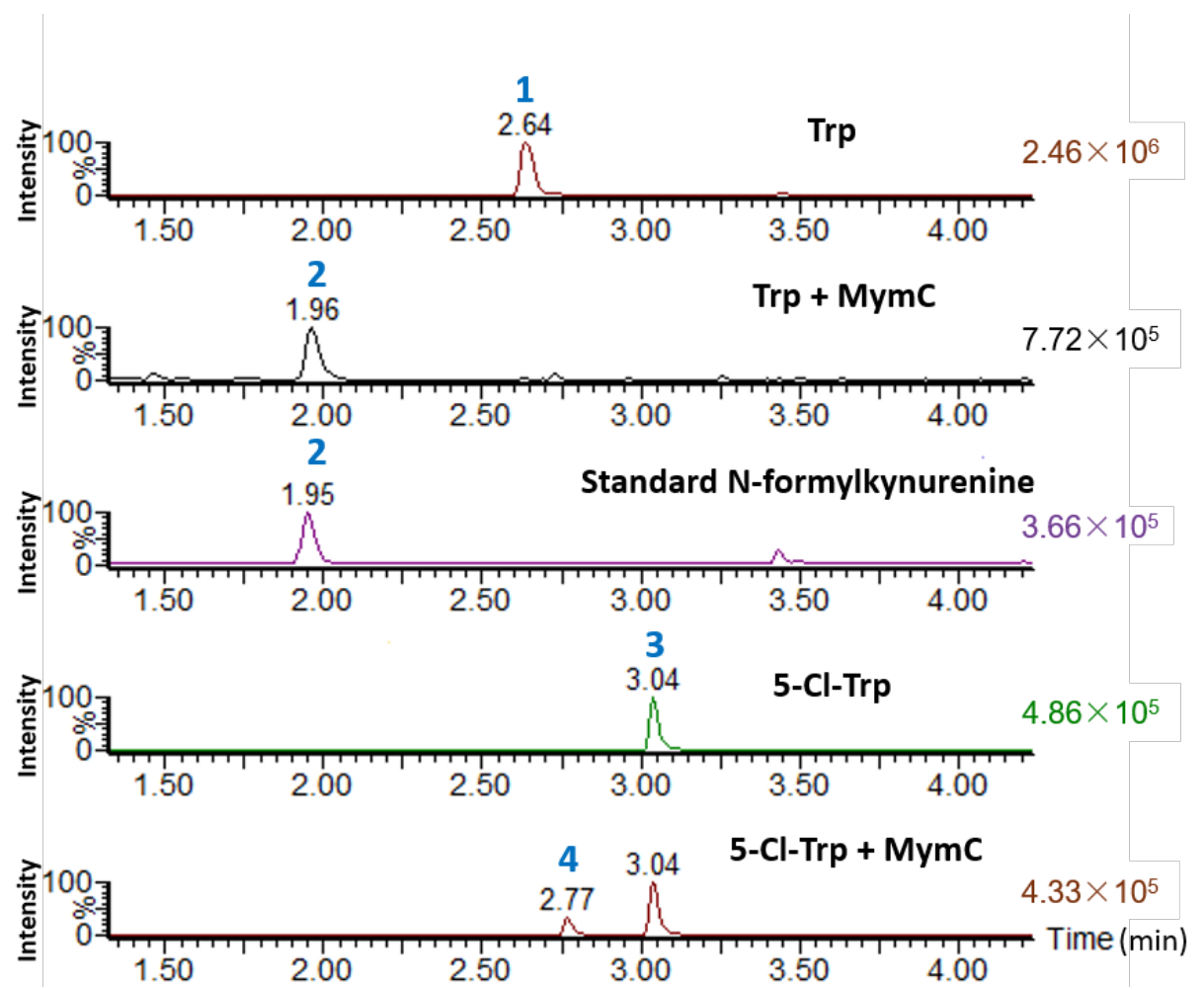

(a)

Figure 3. Cont. 


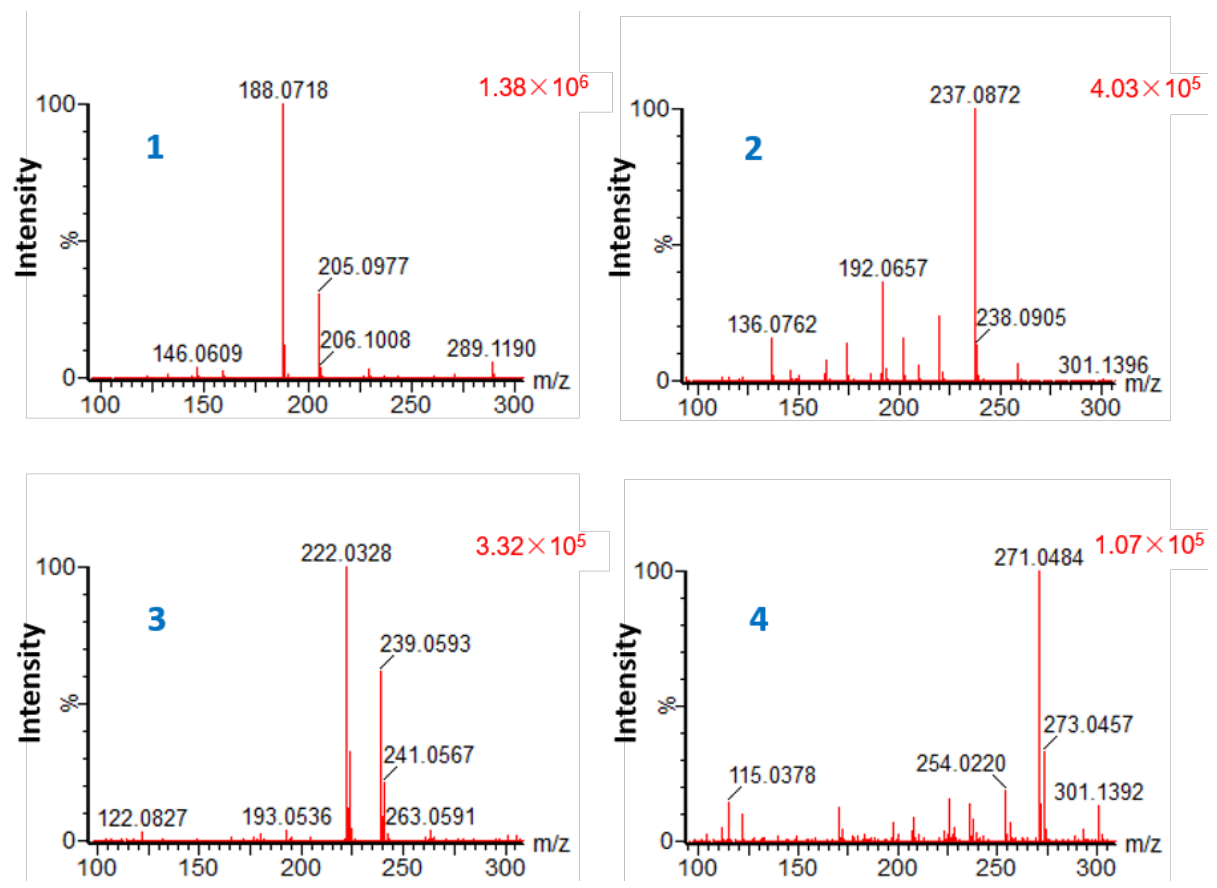

(b)

Figure 3. Ultra-high-performance liquid chromatography (UHPLC)-High-resolution mass spectrometry (HRMS) analyses (a) and High-resolution electrospray ionisation mass spectrometry (HR-ESI-MS) spectra (b) of the products from the in vitro enzymatic assay of MymC. 1: Trp; 2: $N$-formylkynurenine; 3: 5-Cl-Trp; 4: 5-Cl-N-formylkynurenine.

Unfortunately, heterologous expression of MymD, MymM, and MymP in E. coli failed despite the use of several strategies, including changing the specialized host strains, fusion protein technology, codon optimization, etc. MymD and MymM were expressed as inclusion bodies and MymP was not expressed in E. coli. Perhaps molecular chaperones or some uncertain culture conditions were essential for these recombinant proteins to fold properly.

\subsection{Identification of the Mycemycin Biosynthetic Gene Cluster in S. sp. FXJ1.235}

To verify that the predicted mye gene cluster was responsible for mycemycin biosynthesis in S. sp. FXJ1.235, the roles of myeD, myeG, myeO, and myeP were investigated by constructing four corresponding disruption mutants. For $m y e D$, which encodes an amidohydrolase, a mutant $\triangle m y e D$ containing a $1410 \mathrm{bp}$ in-frame deletion within this gene was constructed. UHPLC-HRMS analysis of culture extracts showed that the production of both mycemycins A and B was abolished in this mutant (Figure 4). Disruption of $m y e G$, which was predicted to encode a 3-oxoacyl-ACP synthase, was performed by replacing a $1045 \mathrm{bp}$ fragment of this gene with the kanamycin resistance gene neo via a double-crossover homologous recombination. UHPLC-HRMS analysis also showed that the mutant $\triangle m y e G$ no longer produced mycemycins (Figure 4). Inactivation of myeP, which encoded a 511-amino acid halogenase, was performed through the same knockout strategy as $\Delta m y e G$. This resulted in the abolishment of mono-halogenated mycemycin B production but did not interfere with the synthesis of the non-halogenated mycemycin A (Figure 4). These results confirmed that MyeD and MyeG were essential for mycemycin biosynthesis and MyeP was responsible for the post-halogenation of mycemycin in S. sp. FXJ1.235.

In addition, UHPLC-HRMS analysis of a mutant containing a $396 \mathrm{bp}$ in-frame deletion within $m y e O$, a putative flavin reductase gene, showed that neither mycemycin A nor B was abolished, indicating that myeO was not essential for mycemycin biosynthesis in S. sp. FXJ1.235 (Figures 4 and S1). 


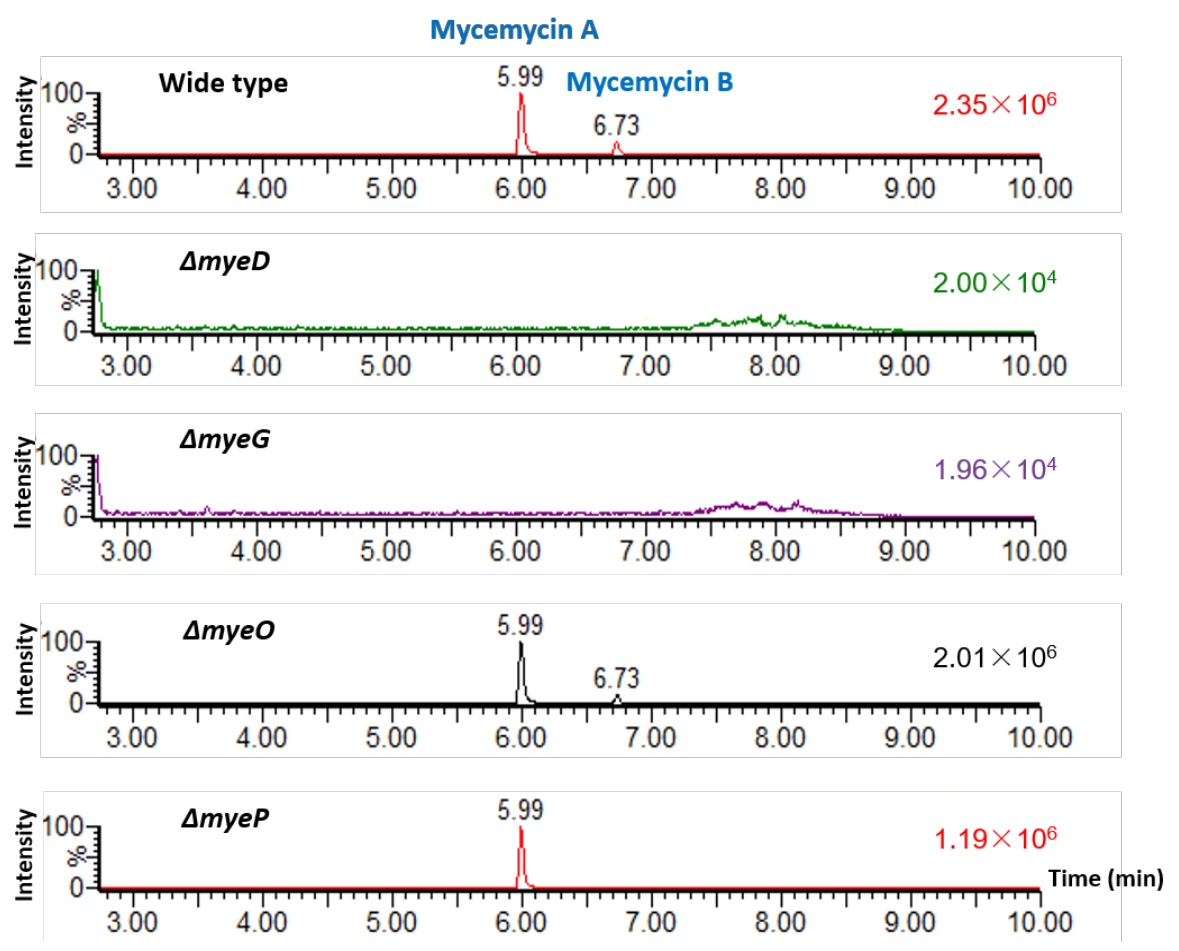

Figure 4. UHPLC-HRMS analyses of fermentation mycelium extracts of $S$. sp. FXJ1.235 wild type and its four mutants. The HR-ESI-MS spectra of mycemycins A and B are shown in Figure S1.

$\mathrm{MyeO}$ and MyeP were proposed to form a two-component halogenase system [17,18]. In this system, the halogenation by $\mathrm{MyeP}$ needed the flavin reductase $\mathrm{MyeO}$ to catalyze the nicotinamide adenine dinucleotide-dependent reduction of flavin adenine dinucleotide which would provide the $\mathrm{FADH}_{2}$ for the halogenase [19]. However, several halometabolite biosynthesis gene clusters were found to be free of flavin reductase genes and the $\mathrm{FADH}_{2}$ needed may have been supplied by flavin reductases encoded elsewhere in the genome $[18,20]$. In S. sp. FXJ1.235, there were at least three putative flavin reductases encoded in the genome, and therefore, based on the result of the mutant $\Delta m y e O$, the other two flavin reductases might have supplied the $\mathrm{FADH}_{2}$ for halogenation during mycemycin B biosynthesis.

\subsection{Feeding S. sp. FXJ1.235 with 5-Cl-Trp}

To verify whether $S$. sp. FXJ1.235 could use 5-Cl-Trp to synthesize DBP dichloride derivatives similar to mycemycin C, 5-Cl-Trp was added to the fermentation medium. UHPLC-HRMS analysis showed no changes to the products in the resulting mycelium extracts but also identified an additional product in the fermentation liquid extracts (Figure 5a). However, the additional product was still mono-chlorinated. Its molecular formula was established as $\mathrm{C}_{7} \mathrm{H}_{6} \mathrm{ClNO}_{2}$ according to the $[\mathrm{M}+\mathrm{H}]^{+}$ peak at $m / z 172.0170$ in HR-ESI-MS (Figure 5b) and the UV absorption at 208, 248, and $321 \mathrm{~nm}$, respectively (Figure S2). Thus, this product was predicted to be 5-Cl-anthranilic acid; its chemical structure is shown in Figure 5a.

The structure of the additional product was very similar to that of anthranilic acid and was not hydroxylated. Considering the predicted functions of the mye genes, it is very likely that $S$. sp. FXJ1.235, 5-Cl-Trp can be converted to 5-Cl-anthranilic acid by successive enzymatic reactions of TDO (MyeC), amidohydrolase (MyeD), and KYN (MyeQ). However, the resulting 5-Cl-anthranilic acid could not be recognized by the subsequent enzymes responsible for the coupling of the anthranilic acid to the salicylic acid. This result suggested that some of the enzymes involved in the mycemycin 
biosynthesis in S. sp. FXJ1.235 had different substrate specificity than their counterparts in S. olivaceus FXJ8.012 $\Delta 1741$.

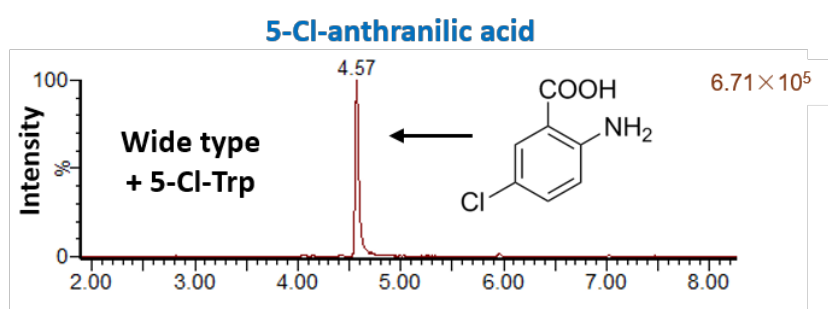

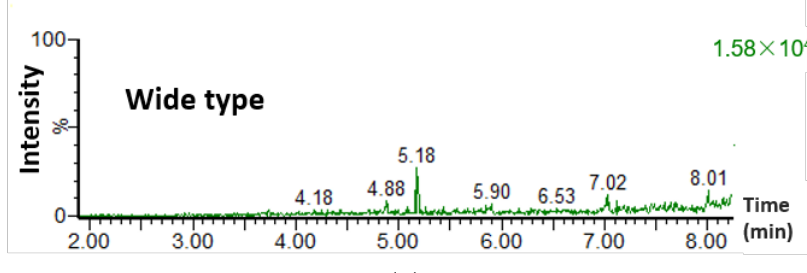

(a)

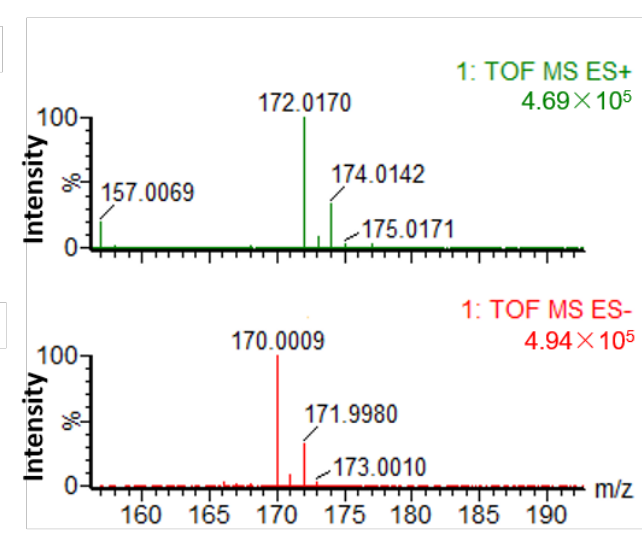

(b)

Figure 5. (a) UHPLC-HRMS analyses of fermentation liquid extracts of $S$. sp. FXJ1.235 feeding with 0.2 $\mathrm{mM}$ (final concentration) 5-Cl-Trp; (b) HR-ESI-MS spectra of the additional product 5-Cl-anthranilic acid in the feeding experiment.

\subsection{Proposed Pathways for Mycemycin Biosynthesis}

Based on the results and analyses above, the biosynthetic pathways of mycemycin biosynthesis in S. olivaceus FXJ8.012 1741 and S. sp. FXJ1.235 are proposed and shown in Figures 6 and S3, respectively. Initially, Trp was catalyzed by MymC/MyeC, a TDO, through the oxidative cleavage of the pyrrole ring and halogenated by MymM at the C-5 position of the benzene ring, resulting in NFK in S. sp. FXJ1.235 and 5-Cl-NFK in S. olivaceus FXJ8.012 1741 . The initial halogenation was absent during the biosynthesis of mycemycins A and B in S. sp. FXJ1.235, since their chemical structures lacked chlorine atoms at this position. This prediction is consistent with the fact that the mye gene cluster contained only one halogenase gene while the mym gene cluster contained two. The amido bond of 5-Cl-NFK/NFK was cleaved by the amidohydrolase MymD/MyeD, resulting in 5-Cl-kynurenine/kynurenine. The alanine side chain of the latter was cleaved by the putative kynureninase, $\mathrm{MymQ} / \mathrm{MyeQ}$, to form 5-Cl-anthranilic acid/anthranilic acid $[10,15]$. The putative methyltransferase MymB catalyzed methylation at the C- 6 position of benzene ring to produce 5-Cl-6-methyl-anthranilic acid in S. olivaceus FXJ8.012 11741 . This step of methylation was also absent for mycemycins A and B, as their chemical structures lacked methyl groups at the same position. Moreover, salicylic acid was generated from chroismic acid by MymA/MyeA, and was loaded onto the $N^{\prime}$-terminal peptidyl carrier protein domain of MymE/MyeE to yield salicyl thioester [21,22]. Next, the unusual beta-ketoacyl-ACP synthase, MymG/MyeG, catalyzed the formation of an amide bond between 5-Cl-6-methyl-anthranilic acid/anthranilic acid and salicyl thioester to generate 5-Cl-6-methyl-( $\mathrm{N}$-salicyloyl)anthranilic acid/ $\mathrm{N}$-salicyloyl anthranilic acid [23]. The ether moiety was formed by oxidative coupling, potentially resulting from a diradical on the salicylic phenol and ortho to the amide of the anthranilic ring. Such oxidative couplings of phenolic compounds to ethers are known in bacteria, catalyzed by cytochrome P450 (CYP450) enzymes [24,25]. As we did not find any CYP450 genes in the mycemycin gene clusters, this reaction might be catalyzed by one of the multiple CYP450s encoded elsewhere in the genomes. Subsequently, the intermediate in S. olivaceus FXJ8.012 1741 was aminated at the carboxyl group to yield mycemycin D and then halogenated by the putative halogenase $\mathrm{MymP}$ at the C-5 position of the other benzene ring to yielded mycemycin E, or was methylated by MymJ at the carboxyl group and halogenated by MymP to generate mycemycin C (Figure 6). In S. sp. FXJ1.235, methylation and halogenation followed, producing mycemycins A and B (Figure S3). 


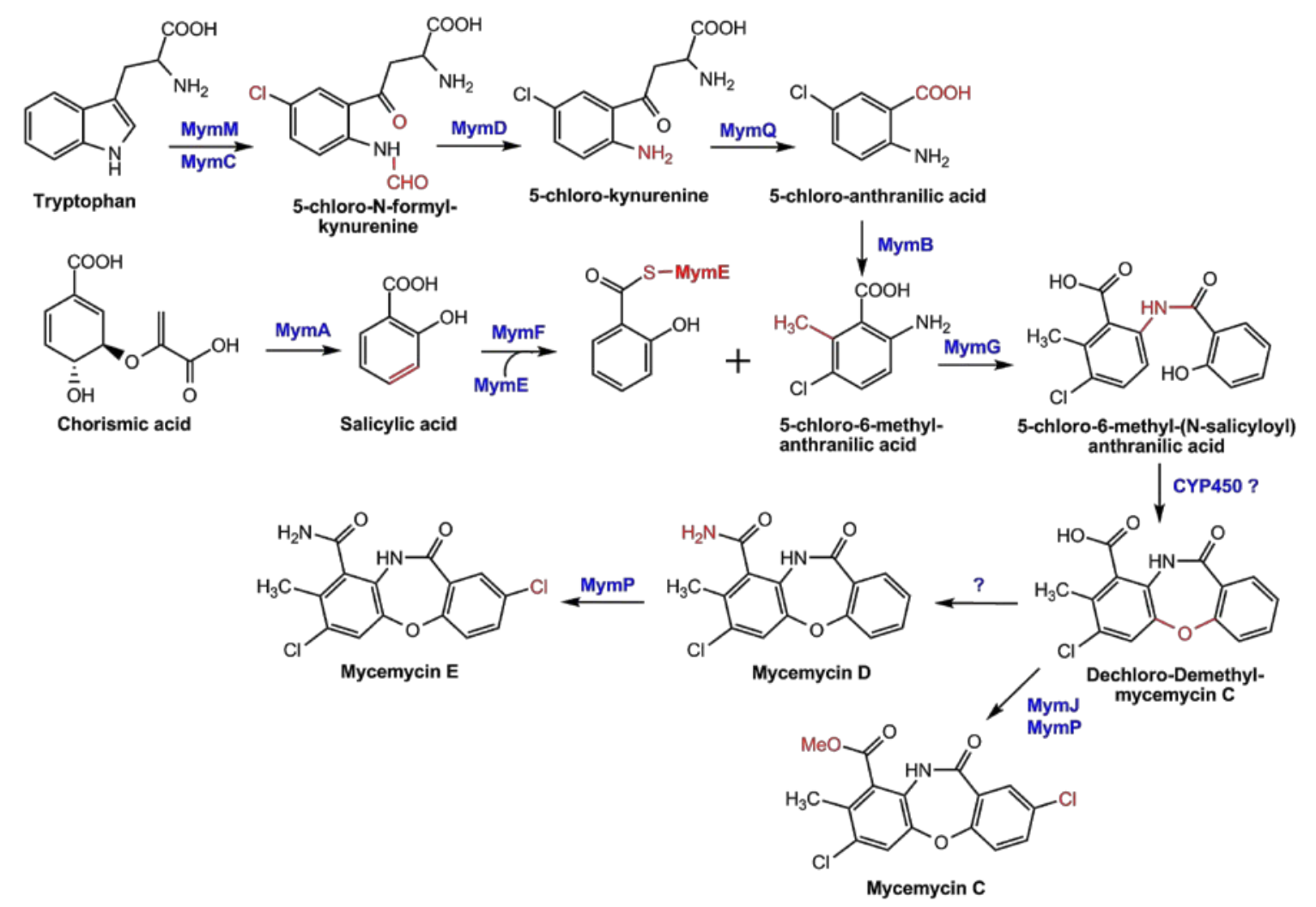

Figure 6. Proposed pathway for the biosynthesis of mycemycins C-E in S. olivaceus FXJ8.012 1741. The pathway for mycemycins A and B in S. sp. FXJ1.235 is shown in Figure S3.

It is interesting that S. olivaceus FXJ8.012 1741 and S. sp. FXJ1.235 had similar proposed biosynthetic pathways for mycemycins even though they were derived from different habitats, belonged to different species, and possessed mycemycin biosynthetic gene clusters with quite different genomic arrangements. Combined with the revelation of the feeding experiment result, we concluded that the two strains had gone through different evolutionary processes in marine and terrestrial habitats, respectively, to acquire and shape their mycemycin biosynthesis systems.

Mycemycin biosynthesis is supplied with precursors or intermediates from the primary metabolism which is not rare during secondary metabolites biosynthesis in actinobacteria [26]. S. sp. FXJ1.235 even engages two primary metabolic enzymes, TDO and KYN, for mycemycin biosynthesis. Perhaps the crosstalk between primary and secondary metabolisms provides a unique advantage for antibiotic-producing strains to balance the excess of nutrient substances and survive in harsh, nutrient-limited environments [27,28].

\section{Materials and Methods}

\subsection{Strains, Plasmids and Media}

Bacterial strains, plasmids, and primers used in this study are listed in Tables S2 and S3 in the Supporting Information. Detailed information of S. olivaceus FXJ8.012 $\Delta 1741$ and S. sp. FXJ1.235 was reported previously [7]. Escherichia coli Top 10 was used for propagating plasmids and E. coli ET12567/pUZ8002 was used for conjugation between E. coli and streptomycetes.

Streptomyces strains were grown on glucose-yeast extract-malt extract (GYM) agar medium at $28^{\circ} \mathrm{C}$ for sporulation. GYM medium with $1 \mathrm{~g} / \mathrm{L} \mathrm{NaCl}$ was used as the fermentation medium for FXJ1.235, while modified R2 medium was used for FXJ8.012 1741 . The culture conditions for mycemycin production were generally as described previously [7]. In short, spore suspensions were inoculated 
in $250 \mathrm{~mL}$ shake flasks containing $100 \mathrm{~mL}$ liquid GYM medium, which were then incubated as seed culture on a rotary shaker at $220 \mathrm{rpm}$ and $28^{\circ} \mathrm{C}$ for two days. Then $1 \mathrm{~mL}$ seed medium culture was transferred into a $250 \mathrm{~mL}$ shake flasks containing $100 \mathrm{~mL}$ fermentation medium. The inoculated flasks were incubated under similar conditions for seven days. E. coli strains carrying plasmids for nucleic acid manipulation were cultured in liquid or agar LB medium. When necessary, antibiotics were added at the following concentrations: ampicillin at $100 \mu \mathrm{g} / \mathrm{mL}$, apramycin or kanamycin at $50 \mu \mathrm{g} / \mathrm{mL}$, chloramphenicol at $25 \mu \mathrm{g} / \mathrm{mL}$, and nalidixic acid at $25 \mu \mathrm{g} / \mathrm{mL}$.

\subsection{Genome Sequencing and Annotation}

Genomic DNAs were extracted according to standard approaches [29]. Genome sequencing of S. olivaceus FXJ8.012 1741 was performed using Illumina genomic analyzer (Beijing Genomics Institute, Shenzhen, China), resulting in a total of 8,326,611 bp of genome sequence distributed across 519 contigs ( $\geq 500 \mathrm{bp}$ ). The genome of $S$. sp. FXJ1.235 was sequenced using an Illumina Hiseq system (Novogene, Beijing, China), resulting in a total of $8,852,829$ bp of genome sequence distributed across 48 contigs ( $\geq 600 \mathrm{bp}$ ). The sequences obtained were annotated using Glimmer 3.02 [30], GeneMarkS [31], and BlastP [14]. The DNA sequences of mycemycin gene clusters have been deposited in the GenBank database. The accession number for mym is MG837055 and the numbers for mye are MG837053 (part I: myeC, myeQ, and orf-1 orf-3) and MG837054 (part II: the other mye genes and orf-4 orf-6).

\subsection{Heterologous Expression and In Vitro Activity Assay of the TDO MymC}

The TDO-encoding gene mymC was amplified from the S. olivaceus FXJ8.012 1741 genome DNA with primer pairs mymC-EF and mymC-ER. The amplimer was digested by HindIII/EcoRI after purification by agarose gel electrophoresis and then ligated with HindIII/EcoRI-digested plasmid pET28a to generate pET28a::mymC. Further verification was performed by PCR with primer pairs $T 7$ and T7ter and sequencing of the resulting amplimers. The recombinant plasmid was then transferred into E. coli rosetta (DE3).

Protein expression was induced by $0.5 \mathrm{mM}$ isopropyl-b-D-thiogalactopyranoside (IPTG) in an LB medium containing $0.05 \mathrm{mg} / \mathrm{mL}$ kanamycin and $0.1 \mathrm{mg} / \mathrm{mL}$ heme at $15{ }^{\circ} \mathrm{C}$ for $20 \mathrm{~h}$. The harvested cell pellets were resuspended in binding buffer $[20 \mathrm{mM}$ Tris- $\mathrm{HCl}(\mathrm{pH} \mathrm{8.0)}, 100 \mathrm{mM} \mathrm{NaCl}, 20 \mathrm{mM}$ imadazole, $1 \mathrm{mM}$ PMSF (phenylmethanesulfonyl fluoride) and 10\% glycerol at $\mathrm{pH}$ 8.0] and lysed by sonication on ice. The resulting lysate was clarified by centrifugation and the supernatant was purified through $\mathrm{Ni}^{2+}$ affinity chromatograph strategy using a HisTrap HP column (GE Healthcare, Piscataway, NJ, USA). In brief, the supernatant was loaded onto a $5 \mathrm{~mL}$ pre-equilibrated HisTrap HP column and the bound protein was eluted with a linear gradient of 20 to $500 \mathrm{mM}$ imidazole. The protein was then loaded onto a PD-10 desalting column (GE Healthcare) to remove imidazole and eluted with a desalting buffer [20 mM Tris- $\mathrm{HCl}(\mathrm{pH} 8.0), 100 \mathrm{mM} \mathrm{NaCl}$ and $10 \%(w / v)$ glycerol]. Purified proteins were analyzed on $12 \%$ SDS-PAGE and the protein concentration was determined using a Pierce ${ }^{\mathrm{TM}}$ BCA protein assay kit (Thermo Scientific, Waltham, MA, USA).

Analysis of the in vitro activity of MymC was carried out by detecting the product formation at $321 \mathrm{~nm}\left(\varepsilon=3750 \mathrm{M}^{-1} \mathrm{~cm}^{-1}\right.$ for $N$-formylkynurenine) [16]. The in vitro assay reaction $(200 \mu \mathrm{L})$ was performed at $28{ }^{\circ} \mathrm{C}$ for $2 \mathrm{~h}$ which comprised of $20 \mathrm{mM}$ Tris- $\mathrm{HCl}$ (pH 7.5), $100 \mathrm{mM} \mathrm{NaCl}, 10 \mathrm{mM}$ ascorbic acid, $40 \mathrm{mM}$ substrate, and $25 \mu \mathrm{M}$ MymC solution. Subsequently, the reaction was stopped by adding an equal volume of methanol and analyzed by UHPLC.

\subsection{Mutant Construction and Confirmation}

Nucleic acid manipulations for E. coli and streptomycetes were performed according to standard approaches $[29,32]$.

The $\Delta m y e P$ and $\triangle m y e G$ mutants were constructed as follows. The kanamycin resistance gene neo was amplified from pUC119::neo using primers neo-BglII- $F$ and neo- $B g l \mathrm{II}-\mathrm{R}$ (Table S4). Upstream and downstream regions of approximately $2 \mathrm{~kb}$ flanking myeP were amplified from S. sp. FXJ1.235 
genomic DNA using primer pairs myeP-LF/myeP-LR and myeP-RF/myeP-RR. These amplimers were separated by agarose gel electrophoresis and purified from the gel. The resulting DNA fragments were mixed with neo gene and EcoRV-digested plasmid pKC1139 to generate pKC1139::myeP::neo using Gibson isothermal assembly [33]. The recombinant plasmid was subsequently introduced into $S$. sp. FXJ1.235 by conjugation via ET12567/pUZ8002. Spores of exconjugants were harvested and spread on MS agar [29] containing kanamycin. After incubation at $40{ }^{\circ} \mathrm{C}$ for three days, apramycin-sensitive and kanamycin-resistant colonies were identified and further confirmed as myeP disruption mutants $(\triangle m y e P)$ by PCR with primer pairs myeP-F and myeP-R along with a sequencing of the resulting amplimers. The $\triangle m y e G$ mutant was constructed and verified in an analogous manner.

The $\Delta m y e O$ and $\triangle m y e D$ mutants were constructed as described above with minor modification. For $\Delta m y e O$, a $396 \mathrm{bp}$ in-frame deletion extending from position +95 to +490 within $m y e O$ was performed. As for $\Delta m y e D$, a $1410 \mathrm{bp}$ fragment from +92 to +1501 within $m y e D$ was also knocked out through in-frame deletion. After a temperature-sensitive experiment, apramycin-sensitive colonies were selected and further confirmed as target gene disruption mutants by PCR with corresponding primer pairs (Table S4) and sequencing of the resulting amplimers.

The mutants and wild type were fermented as mentioned above and the mycelium was extracted with enthanol as described previously [7].

\subsection{Feeding Experiments}

S. sp. FXJ1.235 was precultured as mentioned above for the seed culture and $1 \mathrm{~mL}$ seed culture was transferred into a $250 \mathrm{~mL}$ shake flask containing $100 \mathrm{~mL}$ fermentation medium supplemented with $0.2 \mathrm{mM}$ (final concentration) 5-Cl-Trp. After incubation under similar conditions for seven days, the culture broth was centrifugated. The resulting mycelium was extracted with enthanol as described previously [7] and the supernatant was extracted twice with equal volumes of ethyl acetate. The extracts were then concentrated to dryness under vacuum.

\subsection{Ultra-High-Performance Liquid Chromatography-High-Resolution Mass Spectrometry}

The extracts above were redissolved separately in methanol and passed through a $0.45 \mu \mathrm{m}$ membrane. A $2 \mu \mathrm{L}$ of sample was then injected into a Waters ACQUITY UPLC BEH $C_{18}$ column $\left(2.1 \mathrm{~mm} \times 50 \mathrm{~mm}, 1.7 \mu \mathrm{m}, 45^{\circ} \mathrm{C}\right)$ connected to a Waters ACQUITY UPLC / Xevo G2 Qtof MS system (Waters Corporation, Milford, MA, USA) equipped with an electrospray source. The column was eluted as follows: $0 \mathrm{~min}-95 \% \mathrm{~A}+5 \% \mathrm{~B}, 10 \mathrm{~min}-0 \% \mathrm{~A}+100 \% \mathrm{~B}$, where $\mathrm{A}$ was water containing $0.1 \%$ formic acid and $\mathrm{B}$ was acetonitrile. The full scan data were acquired in the positive ion mode from 50 to 1200 Da with a $0.2 \mathrm{~s}$ scan time using the following settings: capillary voltage $3.0 \mathrm{kV}$; de-solvation temperature $350{ }^{\circ} \mathrm{C}$; sample cone voltage $35 \mathrm{~V}$; extraction cone voltage $4 \mathrm{~V}$; source temperature $120^{\circ} \mathrm{C}$; cone gas flow $50 \mathrm{~L} / \mathrm{h}$; and desolvation gas flow $800 \mathrm{~L} / \mathrm{h}$. The mass spectrometer was calibrated across the mass range of 50-1200 Da using a solution of sodium formate. Data were centroided and $m / z$ values were corrected during acquisition using an external reference consisting of a $0.2 \mathrm{ng} / \mathrm{mL}$ solution of leucine enkephalin infused at a flow rate of $5 \mu \mathrm{L} / \mathrm{min}$ via a lockspray interface, generating a reference ion at $556.2771 \mathrm{Da}\left([\mathrm{M}+\mathrm{H}]^{+}\right)$. The lockspray scan time was set at $0.5 \mathrm{~s}$ with an interval of $15 \mathrm{~s}$ and data were averaged over three scans.

\section{Conclusions}

In this study, we applied bioinformatics analyses, heterologous expression for S. olivaceus FXJ8.012 $\Delta 1741$, genetic manipulation, and a feeding experiment in S. sp. FXJ1.235, leading to the identification of divergent mycemycin biosynthetic gene clusters and the detection of similar proposed biosynthetic pathways in the two strains. It is the first report of DBP biosynthetic gene clusters and pathways. These findings also establish a foundation for biosynthesis of DBP derivatives with desired bioactivities. 
Supplementary Materials: The following are available online at http://www.mdpi.com/1660-3397/16/3/98/s1, Table S1: Genes and proteins involved in mycemycin biosynthesis and their putative functions in S. sp. FXJ1.235; Table S2: Strains used in this study; Table S3: Plasmids used in this study; Table S4: Primers used in this study; Figure S1: HR-ESI-MS spectra of mycemycin A (a) and mycemycin B (b); Figure S2: UV spectrum of 5-Cl-anthranilic acid; Figure S3: Proposed pathway for the biosynthesis of mycemycins A and B in S. sp. FXJ1.235.

Acknowledgments: This research was supported by the program of China Ocean Mineral Resources R\&D Association (grant No. DY135-B-02) and by the National Natural Science Foundation of China (grant No. 81773615). We thank Guoming Ai (Institute of Microbiology, Chinese Academy of Sciences) for assisting the MS analysis. We are also grateful to the anonymous reviewers for the constructive comments on the biosynthetic pathways.

Author Contributions: Y.H. and Y.C. conceived and designed the research; F.S., N.L. and M.L. performed the experiments; F.S., Y.H. and Y.C. analyzed the data; F.S. and Y.H. wrote the paper with contributions from all other authors.

Conflicts of Interest: The authors declare no conflict of interest.

\section{References}

1. Guo, X.L.; Zhang-Negrerie, D.; Du, Y.F. Iodine(III)-mediated construction of the dibenzoxazepinone skeleton from 2-(aryloxy) benzamides through oxidative C-N formation. RSC Adv. 2015, 5, 94732-94736. [CrossRef]

2. Fiorentino, A.; D’Abrosca, B.; Pacifico, S.; Cefarelli, G.; Uzzo, P.; Monaco, P. Natural dibenzoxazepinones from leaves of Carex distachya: Structural elucidation and radical scavenging activity. Bioorg. Med. Chem. Lett. 2007, 17, 636-639. [CrossRef] [PubMed]

3. Chen, Y.; Peng, Q.; Zhang, R.; Hu, J.; Zhou, Y.; Xu, L.; Pan, X. Ligand-controlled chemoselective one-pot synthesis of dibenzo-thiazepinones and dibenzoxazepinones via twice copper-catalyzed cross-coupling. Synlett 2017, 28, 1201-1208.

4. Zhou, Y.; Zhu, J.; Li, B.; Zhang, Y.; Feng, J.; Hall, A.; Shi, J.; Zhu, W. Access to different isomeric dibenzoxazepinones through copper-catalyzed $\mathrm{C}-\mathrm{H}$ etherification and $\mathrm{C}-\mathrm{N}$ bond construction with controllable Smiles rearrangement. Org. Lett. 2016, 18, 380-383. [CrossRef] [PubMed]

5. Liu, S.; Hu, Y.; Qian, P.; Hu, Y.; Ao, G.; Chen, S.; Zhang, S.; Zhang, Y. An efficient cascade approach to dibenzoxazepinones via nucleophilic aromatic substitution and Smiles rearrangement. Tetrahedron Lett. 2015, 56, 2211-2213. [CrossRef]

6. Hone, N.D.; Salter, J.I.; Reader, J.C. Solid-phase synthesis of dibenzoxazepinones. Tetrahedron Lett. 2003, 44, 8169-8172. [CrossRef]

7. Liu, N.; Song, F.; Shang, F.; Huang, Y. Mycemycins A-E, new dibenzoxazepinones isolated from two different Streptomycetes. Mar. Drugs 2015, 13, 6247-6258. [CrossRef] [PubMed]

8. Sono, M.; Roach, M.P.; Coulter, E.D.; Dawson, J.H. Heme-containing oxygenases. Chem. Rev. 1996, 96, 2841-2888. [CrossRef] [PubMed]

9. Forouhar, F.; Anderson, J.L.R.; Mowat, C.G.; Vorobiev, S.M.; Hussain, A.; Abashidze, M.; Bruckmann, C.; Thackray, S.J.; Seetharaman, J.; Tucker, T.; et al. Molecular insights into substrate recognition and catalysis by tryptophan 2,3-dioxygenase. Proc. Natl. Acad. Sci. USA 2007, 104, 473-478. [CrossRef] [PubMed]

10. Kurnasov, O.; Goral, V.; Colabroy, K.; Gerdes, S.; Anantha, S.; Osterman, A.; Begley, T.P. NAD biosynthesis: Identification of the tryptophan to quinolinate pathway in Bacteria. Chem. Biol. 2003, 10, 1195-1204. [CrossRef] [PubMed]

11. Hu, Y.; Phelan, V.; Ntai, I.; Farnet, C.M.; Zazopoulos, E.; Bachmann, B.O. Benzodiazepine biosynthesis in Streptomyces refuineus. Chem. Biol. 2007, 14, 691-701. [CrossRef] [PubMed]

12. Keller, U.; Lang, M.; Crnovcic, I.; Pfennig, F.; Schauwecker, F. The actinomycin biosynthetic gene cluster of Streptomyces chrysomallus: A genetic hall of mirrors for synthesis of a molecule with mirror symmetry. J. Bacteriol. 2010, 192, 2583-2595. [CrossRef] [PubMed]

13. Matthijs, S.; Baysse, C.; Koedam, N.; Tehrani, K.A.; Verheyden, L.; Budzikiewicz, H.; Schafer, M.; Hoorelbeke, B.; Meyer, J.M.; De Greve, H.; et al. The Pseudomonas siderophore quinolobactin is synthesized from xanthurenic acid, an intermediate of the kynurenine pathway. Mol. Microbiol. 2004, 52, 371-384. [CrossRef] [PubMed]

14. Altschul, S.F.; Madden, T.L.; Schaffer, A.A.; Zhang, J.H.; Zhang, Z.; Miller, W.; Lipman, D.J. Gapped BLAST and PSI-BLAST: A new generation of protein database search programs. Nucleic Acids Res. 1997, 25, 3389-3402. [CrossRef] [PubMed] 
15. Li, W.; Khullar, A.; Chou, S.; Sacramo, A.; Gerratana, B. Biosynthesis of sibiromycin, a potent antitumor antibiotic. Appl. Environ. Microbiol. 2009, 75, 2869-2878. [CrossRef] [PubMed]

16. Batabyal, D.; Yeh, S.-R. Human tryptophan dioxygenase: A comparison to indoleamine 2,3-dioxygenase. J. Am. Chem. Soc. 2007, 129, 15690-15701. [CrossRef] [PubMed]

17. Fujimori, D.G.; Hrvatin, S.; Neumann, C.S.; Strieker, M.; Marahiel, M.A.; Walsh, C.T. Cloning and characterization of the biosynthetic gene cluster for kutznerides. Proc. Natl. Acad. Sci. USA 2007, 104, 16498-16503. [CrossRef] [PubMed]

18. Yeh, E.; Garneau, S.; Walsh, C.T. Robust in vitro activity of RebF and RebH, a two-component reductase/halogenase, generating 7-chlorotryptophan during rebeccamycin biosynthesis. Proc. Natl. Acad. Sci. USA 2005, 102, 3960-3965. [CrossRef] [PubMed]

19. Anderson, J.L.R.; Chapman, S.K. Molecular mechanisms of enzyme-catalysed halogenation. Mol. Biosyst. 2006, 2, 350-357. [CrossRef] [PubMed]

20. Milbredt, D.; Patallo, E.P.; van Pée, K.-H. A tryptophan 6-halogenase and an amidotransferase are involved in thienodolin biosynthesis. ChemBioChem 2014, 15, 1011-1020. [CrossRef] [PubMed]

21. Serino, L.; Reimmann, C.; Baur, H.; Beyeler, M.; Visca, P.; Haas, D. Structural genes for salicylate biosynthesis from chorismate in Pseudomonas aeruginosa. Mol. Gen. Genet. 1995, 249, 217-228. [CrossRef] [PubMed]

22. Serino, L.; Reimmann, C.; Visca, P.; Beyeler, M.; Chiesa, V.D.; Haas, D. Biosynthesis of pyochelin and dihydroaeruginoic acid requires the iron-regulated pchDCBA operon in Pseudomonas aeruginosa. J. Bacteriol. 1997, 179, 248-257. [CrossRef] [PubMed]

23. Lv, M.; Zhao, J.; Deng, Z.; Yu, Y. Characterization of the biosynthetic gene cluster for benzoxazole antibiotics A33853 reveals unusual assembly logic. Chem. Biol. 2015, 22, 1313-1324. [CrossRef] [PubMed]

24. Agarwal, V.; Blanton, J.M.; Podell, S.; Taton, A.; Schorn, M.A.; Busch, J.; Lin, Z.; Schmidt, E.W.; Jensen, P.R.; Paul, V.J.; et al. Metagenomic discovery of polybrominated diphenyl ether biosynthesis by marine sponges. Nat. Chem. Biol. 2017, 13, 537-543. [CrossRef] [PubMed]

25. Agarwal, V.; El Gamal, A.A.; Yamanaka, K.; Poth, D.; Kersten, R.D.; Schorn, M.; Allen, E.E.; Moore, B.S. Biosynthesis of polybrominated aromatic organic compounds by marine bacteria. Nat. Chem. Biol. 2014, 10, 640-647. [CrossRef] [PubMed]

26. Bilyk, O.; Luzhetskyy, A. Metabolic engineering of natural product biosynthesis in actinobacteria. Curr. Opin. Biotechnol. 2016, 42, 98-107. [CrossRef] [PubMed]

27. Knoten, C.A.; Hudson, L.L.; Coleman, J.P.; Farrow, J.M.; Pesci, E.C. KynR, a Lrp/AsnC-type transcriptional regulator, directly controls the kynurenine pathway in Pseudomonas aeruginosa. J. Bacteriol. 2011, 193, 6567-6575. [CrossRef] [PubMed]

28. Zummo, F.P.; Marineo, S.; Pace, A.; Civiletti, F.; Giardina, A.; Puglia, A.M. Tryptophan catabolism via kynurenine production in Streptomyces coelicolor: Identification of three genes coding for the enzymes of tryptophan to anthranilate pathway. Appl. Microbiol. Biotechnol. 2012, 94, 719-728. [CrossRef] [PubMed]

29. Kieser, T.; Bibb, M.J.; Buttner, M.J.; Chater, K.F.; Hopwood, D.A. Practical Streptomyces Genetics; John Innes Foundation: Norwich, UK, 2000.

30. Delcher, A.L.; Bratke, K.A.; Powers, E.C.; Salzberg, S.L. Identifying bacterial genes and endosymbiont DNA with Glimmer. Bioinformatics 2007, 23, 673-679. [CrossRef] [PubMed]

31. Besemer, J.; Lomsadze, A.; Borodovsky, M. GeneMarkS: A self-training method for prediction of gene starts in microbial genomes. Implications for finding sequence motifs in regulatory regions. Nucleic Acids Res. 2001, 29, 2607-2618. [CrossRef] [PubMed]

32. Sambrook, J.; Fritsch, E.F.; Maniatis, T. Molecular Cloning; Cold Spring Harbor Laboratory Press: New York, NY, USA, 1989.

33. Gibson, D.G.; Young, L.; Chuang, R.-Y.; Venter, J.C.; Hutchison, C.A., 3rd; Smith, H.O. Enzymatic assembly of DNA molecules up to several hundred kilobases. Nat. Methods 2009, 6, 343-345. [CrossRef] [PubMed]

(C) 2018 by the authors. Licensee MDPI, Basel, Switzerland. This article is an open access article distributed under the terms and conditions of the Creative Commons Attribution (CC BY) license (http:/ / creativecommons.org/licenses/by/4.0/). 